\title{
ЗАКОНОМЕРНОСТИ РАСПРЕДЕЛЕНИЯ КАДАСТРОВЫХ УЧАСТКОВ ГОРОДА ЙОШКАР-ОЛА
}

\section{Мазуркин Петр Матвеевич, Кудряшова Анастасия Игоревна, Фадеев Александр Николаевич}

Поволжский государственный технологический университет, Россия, Йошкар-Ола, kaf_po@mail.ru

Показаны волновые закономерности распределений иентров кадастровых кварталов общественно-деловой зоны города Йошкар-Ола. Предложенный метод статистического моделирования по данным ГИС «Карта-2011» позволяет определить нелинейнье архитектурные оси и направления городской застройки.

Ключевые слова: Город, зоны, квартала, центры, координаты, закономерности.

Введение. Генеральный план городского округа "Город Йошкар-Ола" - столицы Республики Марий Эл - разработан в 2004-2007 гг. Он ставит задачу создать "экологическую и спортивную столицу" Поволжья и для этого есть все основания - красивый, чистый, активно развивающийся город. Поэтому Йошкар-Ола вполне может стать умной и зеленой средой обитания.

Из Генерального плана города нами был выделена основная часть в количестве 303 кадастровых кварталов, по которым в ГИС «Карта-2011» были выделены условные координаты, периметр и площадь квартала в урезанной местной системе координат МСК-12. В статье рассмотрена третья зона с пятью подзонами - общественно-деловая часть города Йошкар-Ола, требующая особого научного обоснования экологических мер по созданию зеленой среды [1-4].

Цель работы: показать возможности статистического моделирования асимметричными вейвлетами распределений координат центров кадастровых кварталов.

Исходные данные. По общественно-деловой зоне координаты центров кадастровых кварталов города Йошкар-Ола приведены в таблице 1.

Таблица 1

Координаты центров кадастровых кварталов общественно-деловой зоны Йошкар-Ола

\begin{tabular}{|r|r|r|r|r|r|r|r|r|r|}
\hline \multicolumn{2}{|c|}{ Подзона 31} & \multicolumn{2}{|c|}{ Подзона 32} & \multicolumn{2}{|c|}{ Подзона 33} & \multicolumn{2}{|c|}{ Подзона 34} & \multicolumn{2}{|c|}{ Подзона 35} \\
\hline $\mathrm{Y}(\mathrm{x}), \mathrm{m}$ & $\mathrm{X}(\mathrm{y}), \mathrm{m}$ & $\mathrm{Y}(\mathrm{x}), \mathrm{m}$ & $\mathrm{X}(\mathrm{y}), \mathrm{m}$ & $\mathrm{Y}(\mathrm{x}), \mathrm{m}$ & $\mathrm{X}(\mathrm{y}), \mathrm{m}$ & $\mathrm{Y}(\mathrm{x}), \mathrm{m}$ & $\mathrm{X}(\mathrm{y}), \mathrm{m}$ & $\mathrm{Y}(\mathrm{x}), \mathrm{m}$ & $\mathrm{X}(\mathrm{y}), \mathrm{m}$ \\
\hline 5888 & 8975 & 2750 & 13247 & 9527 & 10418 & 5098 & 7115 & 8937 & 10338 \\
\hline 6138 & 9712 & 6943 & 7961 & 5087 & 11690 & 1490 & 12226 & 8538 & 9329 \\
\hline 5527 & 9270 & 7997 & 9734 & 4692 & 11834 & 4350 & 8937 & 4350 & 9309 \\
\hline 5527 & 10674 & 8113 & 9825 & 9411 & 8606 & 6035 & 11536 & 2331 & 9382 \\
\hline 6339 & 9596 & 3814 & 8972 & & & 4876 & 12412 & 1601 & 9203 \\
\hline 5401 & 10269 & 5895 & 8569 & & & 6922 & 7339 & 4673 & 6646 \\
\hline 5880 & 10563 & 9910 & 8140 & & & 5014 & 10833 & 1313 & 12179 \\
\hline 5256 & 9822 & 4841 & 8365 & & & 4346 & 8035 & 6193 & 7978 \\
\hline 5632 & 9136 & 8087 & 9233 & & & 4994 & 7783 & & \\
\hline 5421 & 9481 & 3250 & 10851 & & & 4305 & 7827 & & \\
\hline 6037 & 10339 & 4099 & 8872 & & & 4496 & 10839 & & \\
\hline 6916 & 10788 & 8173 & 10109 & & & 10668 & 10517 & & \\
\hline 6550 & 10853 & 4503 & 9215 & & & & & & \\
\hline 5166 & 9576 & 2986 & 10451 & & & & & & \\
\hline 5767 & 9982 & 3755 & 9157 & & & & & & \\
\hline 5666 & 9689 & 5328 & 8067 & & & & & & \\
\hline
\end{tabular}


В таблице 1 даны условные обозначения координат центров кварталов:

$x$ - условная координата центра кадастрового квартала по широте Y (абсцисса), м, $y$ - условная координата центра квартала по долготе X (ордината), м.

Моделирование данных. В большинстве случаев для идентификации искомых закономерностей по известным табличным моделям достаточна усеченная конструкция (по формуле частоты колебания) асимметричного вейвлета $[1,2]$ типа

$$
y=\sum_{i=1}^{m} y_{i}, y_{i}=a_{1 i} x^{a_{2 i}} \exp \left(-a_{3 i} x^{a_{4 i}}\right) \cos \left(\pi x /\left(a_{5 i}+a_{6 i} x^{a_{7 i}}\right)-a_{8 i}\right),
$$

где $y$ - показатель (зависимый фактор), $y_{i}=A_{i} \cos \left(\pi x / p_{i}-a_{8 i}\right), i$ - номер составляющей модели (1), $m$ - количество членов в модели (1), $x$ - объясняющая переменная (влияющий фактор), $a_{1} \ldots a_{8}$ - параметры, принимающие числовые значения в ходе структурно-параметрической идентификации формулы (1), $A_{i}=a_{1 i} x^{a_{2 i}} \exp \left(-a_{3 i} x^{a_{4 i}}\right)$ амплитуда (половина) асимметричного вейвлета (ось $y$ ), $p_{i}=a_{5 i}+a_{6 i} x^{a_{7 i}}-$ полупериод волны колебательного возмущения (ось $x$ ).

На рисунках 1-5 показаны графики вейвлетов по пяти подзонам (табл. 2). Параметры модели (1) для пяти подзон даны в таблице 2.

Подзона 31. Параметры модели (1) в таблице 3 показывают, что по первой составляющей в виде постоянного члена ось общественно-деловой зоны в подзоне 31 городского центра находится на местной долготе 9660 м поперек реки Малая Когшага.
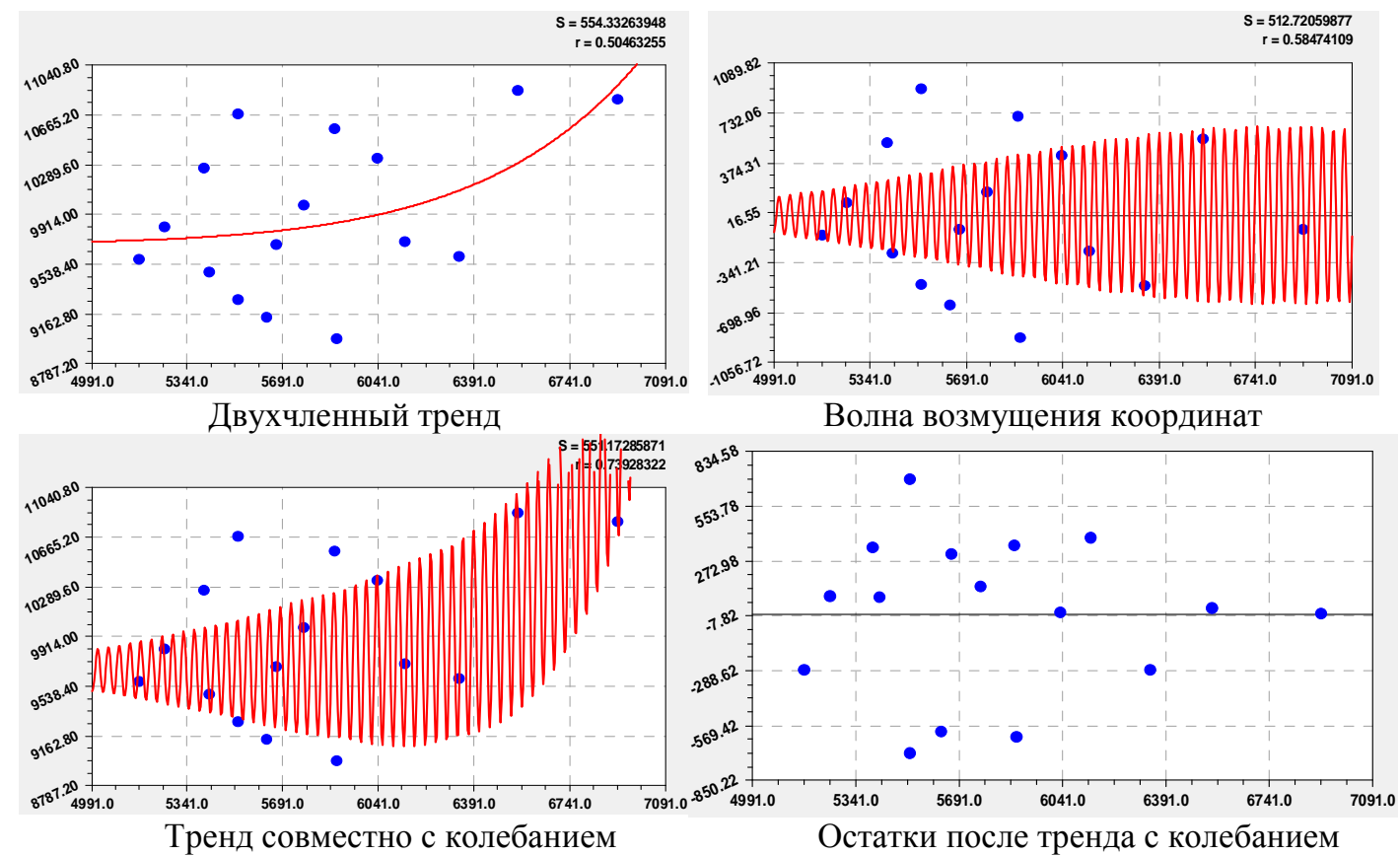

Рис. 1. Графики распределения координат центров кадастровых кварталов в подзоне 31 (в правом верхнем углу графика: $S$ - дисперсия остатков; $r$ - коэффициент корреляции)

По второй составляющей в виде показательного закона со временем эволюции градостроительства ось центральной подзоны 31 сместился на северо-восток, переходя на левую сторону реки Малая Кокшага. Волна возмущения имеет постоянный период в $2 \times 19,66706 \approx 40$ м. Это и есть модуль распределения зданий зоны городского центра вдоль широты или поперек реки. При этом остатки показывают, что при повышении 
точности представлений координат в электронной карте можно выявить и второе колебание непосредственно в старом центре города.

Таблица 2

Функциональная третья зона и подзоны города Йошкар-Ола

\begin{tabular}{|c|l|}
\hline Код & \multicolumn{1}{|c|}{ Наименование } \\
\hline $\mathbf{3}$ & Общественно-деловые зоны (60 кадастровых кварталов) \\
\hline 31 & Зона городского центра \\
\hline 32 & Зона делового, общественного и коммерческого назначения \\
\hline 33 & Зона учреждения здравоохранения и социальной защиты \\
\hline 34 & Зона объектов высшего и среднего профессионального образования \\
\hline 35 & Производственно-деловая зона \\
\hline
\end{tabular}

Для краткой записи значений параметров частных уравнений по обобщенной функции (1) применена матричная форма (табл. 3).

Таблица 3

Параметры вейвлет-сигналов зоны г. Йошкар-Ола

\begin{tabular}{|c|c|c|c|c|c|c|c|c|c|}
\hline \multirow{2}{*}{$\begin{array}{c}\text { № } \\
i\end{array}$} & \multicolumn{4}{|c|}{ Амплитуда колебания (1) } & \multicolumn{4}{|c|}{ Полупериод и сдвиг колебания (1) } & \multirow{2}{*}{$\begin{array}{l}\text { Коэф. } \\
\text { корр. }\end{array}$} \\
\hline & $a_{1 i}$ & $a_{2 i}$ & $a_{3 i}$ & $a_{4 i}$ & $a_{5 i}$ & $a_{6 i}$ & $a_{7 i}$ & $a_{8 i}$ & \\
\hline \multicolumn{10}{|c|}{ Подзона 31} \\
\hline 1 & 9660,0945 & 0 & 0 & 0 & 0 & 0 & 0 & 0 & \multirow{3}{*}{0,7393} \\
\hline 2 & $4,97718 \mathrm{e}-87$ & 23,32631 & 0 & 0 & 0 & 0 & 0 & 0 & \\
\hline 3 & $1,43084 \mathrm{e}-126$ & 37,87247 & 0,0055440 & 1 & 19,66706 & 0 & 0 & 2,59557 & \\
\hline \multicolumn{10}{|c|}{ Подзона 32} \\
\hline 1 & 61012,1486 & 0 & 0,00015790 & 0,99877 & 0 & 0 & 0 & 0 & \multirow{2}{*}{0,8944} \\
\hline 2 & $-2,72353$ & 1,33465 & 0,00049935 & 0,99971 & 0 & 0 & 0 & 0 & \\
\hline \multicolumn{10}{|c|}{ Подзона 33} \\
\hline 1 & 14123,9779 & 0 & 0 & 0 & 0 & 0 & 0 & 0 & \multirow{2}{*}{0,8601} \\
\hline 2 & $-0,48570$ & 1 & 0 & 0 & 0 & 0 & 0 & 0 & \\
\hline \multicolumn{10}{|c|}{ Подзона 34} \\
\hline 1 & $1,82113 \mathrm{e} 6$ & 0 & 0 & 0 & 0 & 0 & 0 & 0 & \multirow{4}{*}{1,0000} \\
\hline 2 & $-1,77808 \mathrm{e} 6$ & 0,0022126 & 0 & 0 & 0 & 0 & 0 & 0 & \\
\hline 3 & 3617,1498 & 0 & 0 & 0 & 603,79737 & 0 & 0 & $-0,62329$ & \\
\hline 4 & $-1,19524 \mathrm{e}-46$ & 14,07210 & 0,0015481 & 1 & 19,98100 & $-0,00032144$ & 1 & $-0,16262$ & \\
\hline \multicolumn{10}{|c|}{ Подзона 35} \\
\hline 1 & $6,20300 \mathrm{e} 5$ & 0 & $-3,91322 \mathrm{e}-6$ & 1 & 0 & 0 & 0 & 0 & \multirow{3}{*}{1,0000} \\
\hline 2 & $-5,47193 \mathrm{e} 5$ & 0,015646 & 0 & 0 & 0 & 0 & 0 & 0 & \\
\hline 3 & 0,0020754 & 1,84764 & 0,00035094 & 1 & 104,08409 & 0,097367 & 0,85742 & 2,65367 & \\
\hline
\end{tabular}

Подзона 32. На рисунке 2 четко выделяется двухчленный тренд с коэффициентом корреляции 0,8944. Этот факт указывает на то, что зона 32 делового, общественного и коммерческого назначения имеет хорошее градостроительную ориентацию.

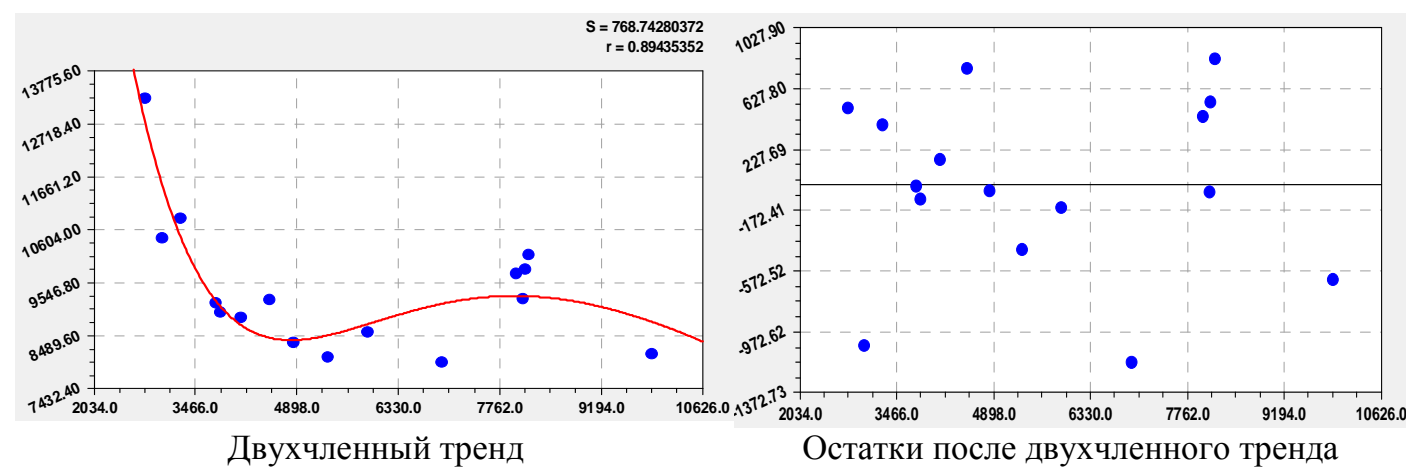

Рис. 2. График распределения центров кадастровых кварталов подзоны 32 делового, общественного и коммерческого назначения 
Подзона 33. По таблице 1 в ней находится всего 4 кадастровых квартала (рис. 3).

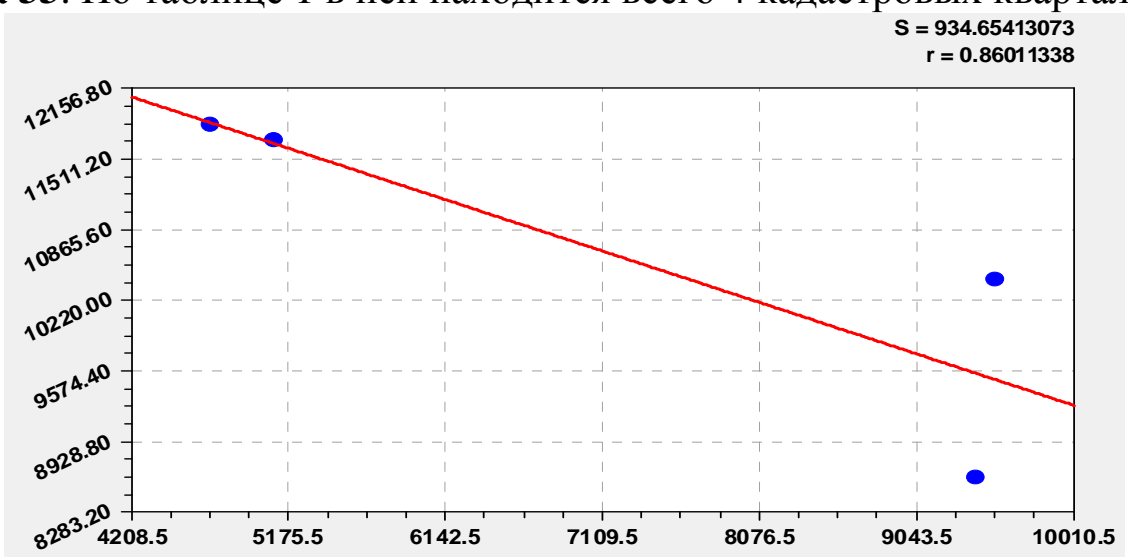

Рис. 3. Подзона 33 учреждений здравоохранения и социальной защиты

Линейная модель дает коэффициент корреляции 0,8601 .

Подзона 34. Она оказалась наиболее сложной (рис. 4).
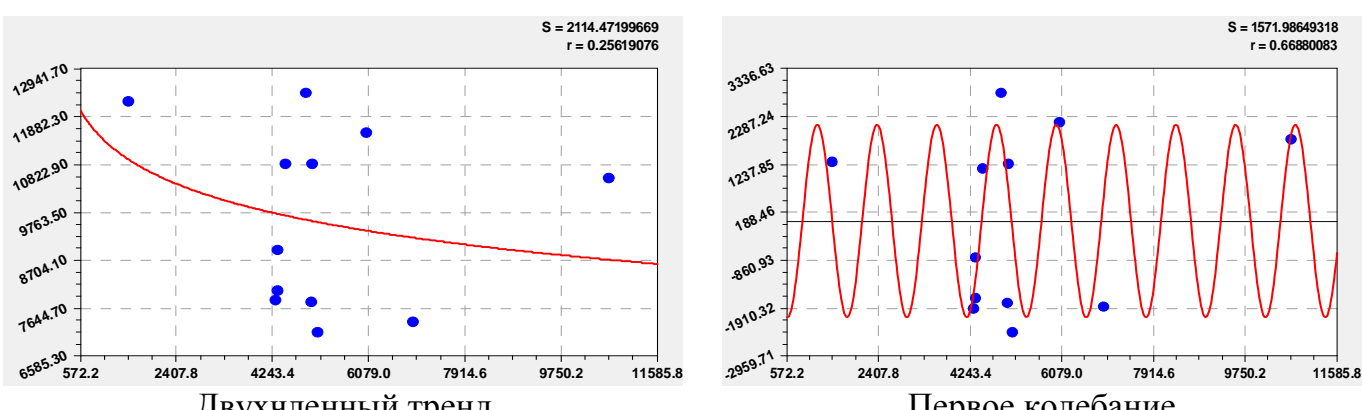

Двухчленный тренд

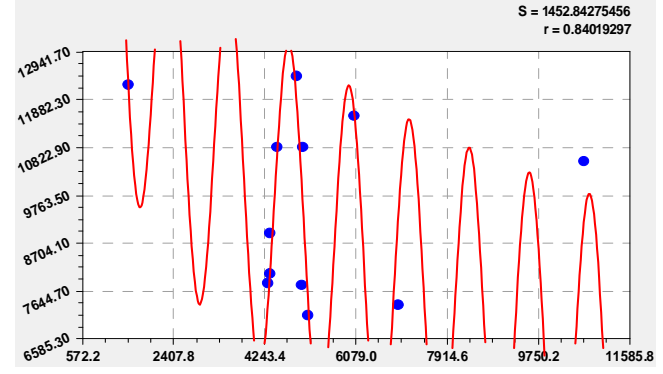

IIep

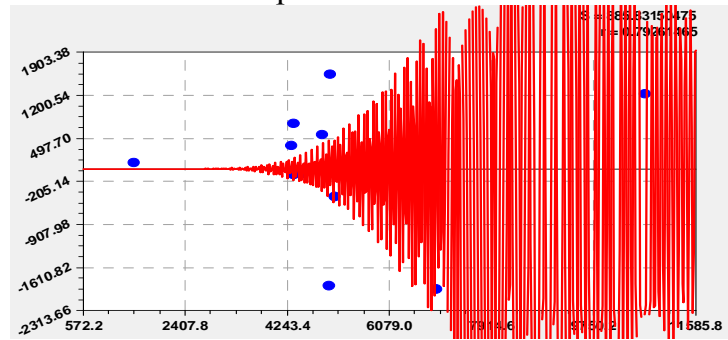

Тренд с первым колебанием

Второе колебание

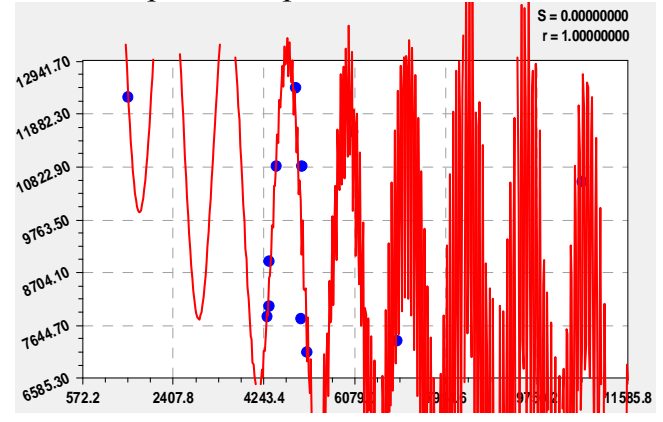

Тренд и два колебания

Рис. 4. Графики возмущения подзоны 34 объектов высшего и среднего профессионального образования

В конце XX века предполагалось построить студенческий городок на левом берегу Малой Кокшаги, поэтому здесь происходит сильное колебание кадастровых кварталов. 
Подзона 35. Производственно-деловая зона (рис. 5) имеет сильное колебание.
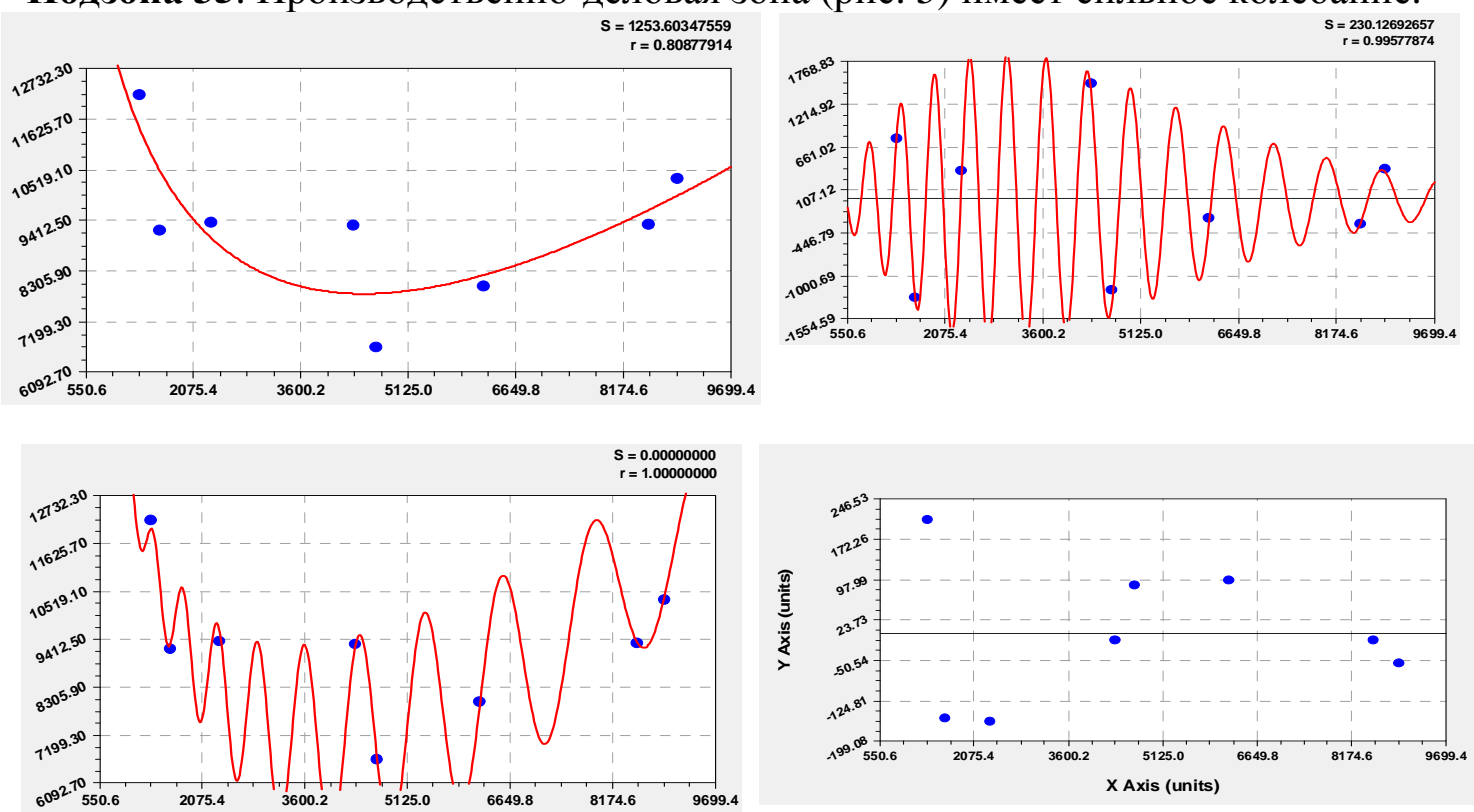

Рис. 5. Графики подзоны 35 производственно-деловой застройки города Йошкар-Ола

Длина колебания охватывает весь город по широте.

Заключение. Статистическое моделирование географического расположения центров городских кадастровых кварталов позволяет изучать архитектурные оси и направления застройки, в том числе и в динамике развития города $[3,4]$. Наиболее устойчивой оказалась зона делового, общественного и коммерческого назначения.

\title{
Список литературы
}

1. Мазуркин П.М., Кудряшова А.И. Динамика онтогенеза листьев дерева. Йошкар-Ола: ПГТУ, 2015. 172 с.

2. Мазуркин П.М., Фадеев А.Н. Геоинформационные системы земельного кадастра, лесного реестра и особо охраняемых территорий // Современные проблемы науки и образования. № 4. 2009. C.69-75.

3. Панасанко С. Город - новая утопия, или горе от ума? 3 февраля 2015. URL: http://greencity.su/novaya-utopiya-ili-gore-ot-uma/ (Дата обращения 18.02.2015).

4. Понятие устойчивого развития. URL: http://green-agency.ru/ponyatie-istoriya-i-sferyustojchivogo-razvitiya/ (Дата обращения 28.02.2015).

\section{REGULARITIES OF DISTRIBUTION OF CADASTRAL PARCELS OF THE CITY OF YOSHKAR-OLA}

\author{
Mazurkin Petr Matveevich, Kudryashova Anastasia Igorevna, \\ Fadeev Aleksandr Nikolayevich \\ VOLGA STATE UNIVERSITY OF TECHNOLOGY, RUSSIA, YOSHKAR-OLA \\ kaf_po@mail.ru
}

Shows the wave patterns of the distributions of the centers of cadastral blocks of public and business zone of the city of Yoshkar-Ola. The proposed method of statistical modeling according to the GIS "Map 2011" allows you to define nonlinear architectural axis and direction of urban development.

Keywords: City, area, cadastral quarter, centers, coordinates, patterns. 